\title{
Electrophysiological findings in entrapment of the median nerve at wrist and elbow
}

\author{
FRITZ BUCHTHAL, ANNELISE ROSENFALCK, AND WERNER TROJABORG
}

\author{
From the Institute of Neurophysiology, University of \\ Copenhagen, and the Laboratory of Clinical \\ Neurophysiology, Rigshospitalet, Copenhagen, Denmark
}

SYNOPSIS In 117 consecutive patients with carpal tunnel syndrome and 11 patients with a compression syndrome of the median nerve at elbow, motor and sensory conduction along the median and ulnar nerves and quantitative electromyography were compared with findings in 190 normal controls of the same age. In $25 \%$ of patients with carpal tunnel syndrome in whom motor conduction and EMG were normal, the lesion was located from abnormalities in sensory conduction. The fact that conduction along the same fibres was moderately slowed from digit to palm, severely slowed across the flexor retinaculum, and normal from wrist to elbow indicates that slowing was due to demyelination at the site of compression. Fifteen per cent of the patients with carpal tunnel syndrome had clinical and electrophysiological signs of ulnar involvement. In the other patients conduction along the ulnar nerve was as in 100 normal controls. Compression at the elbow was located by electromyographical findings rather than by abnormalities in conduction.

The two main sites of entrapment of the median nerves are at the wrist-that is, carpal tunnel syndrome originally described by Ramsay Hunt $(1911,1914)$-and, rarely, at the elbow-that is, pronator syndrome or anterior interosseous nerve syndrome originally described by Seyffarth (1951) and Kiloh and Nevin (1952). In carpal tunnel syndrome Simpson (1956) showed that nerve conduction was often slowed distal to the wrist (references in Gilliatt and Sears, 1958; Thomas and Fullerton, 1963; Buchthal and Rosenfalck, 1971b). In three of the four patients examined with anterior interosseous nerve syndrome motor conduction was normal (Farber and Bryan, 1968; Vichare, 1968; O'Brien and Upton, 1972).

Whether or not slight slowing of nerve conduction can be detected early depends on (1) the scatter of findings in normal subjects, and (2) the length of nerve with normal conduction in series with the section with slowed conduction.

1. In view of the unusually large scatter of motor and sensory latency in normal median nerve (Hongell and Mattsson, 1971) we are presenting data on motor and sensory conduction in a large group of normal subjects under standardized conditions. We have evaluated whether findings in median compared with those in ulnar nerve in the same patient allow mild or borderline cases of entrapment at the wrist to be recognized (Loong and Seah, 1971).

2. We have previously shown that slowing along the median nerve could be demonstrated from palm to wrist in patients with clinical signs and symptoms of carpal tunnel syndrome when conduction from digit to wrist and motor latency were normal (Buchthal and Rosenfalck, 1971b). The present study extends these observations in a larger series of patients.

To record sensory potentials at wrist and at elbow in all patients, the signal-to-noise ratio was improved by using a near-nerve electrode and by averaging many responses (Buchthal and Rosenfalck, 1966a). In this way information was obtained on the conduction of sensory potentials along all segments of the nerve.

3. We have tried to elucidate the mechanism of slowing in conduction by studying the transmission of sensory potentials along fast and slow fibres across the region of entrapment as well as 
proximal and distal to it. If conduction is normal or nearly so in segments of the nerve proximal and distal to the wrist, slowing is due to a local process rather than to loss of large fibres. Motor conduction is of little help in this problem, because it is normal in about a quarter of the patients with entrapment at wrist (Thomas et al., 1967) and because prolonged distal latency was often associated with lesser slowing along the proximal segment of the nerve (Thomas, 1960; Ebeling et al., 1960; Kaeser, 1963; Thomas et al., 1967, Buchthal and Rosenfalck, 1971b).

4. The occasion was taken in a large series of patients with a carpal tunnel syndrome to analyse how partial denervation manifests itself in the parameters of voluntarily initiated and spontaneous electrical activity of muscle.

5. Finally, we report the nerve conduction and electromyographic manifestations of entrapment of the median nerve at elbow.
METHOD

The procedures used for recording sensory and motor conduction have been described (Buchthal and Rosenfalck, 1966a, 1971a, 1971b; Wagner and Buchthal, 1972).

To stimulate sensory fibres maximally with surface electrodes the current was $50-70 \mathrm{~mA}$ or more, with needle electrodes it was $20-30 \mathrm{~mA}(0.2 \mathrm{msec})$. Further increase in stimulus current increased neither the amplitude nor the number of slow components of the response. To stimulate motor fibres the current was 5-7 mA, 10 times the weakest current which just evoked a muscle action potential.

To record from sensory nerve fibres at the wrist and elbow or to stimulate motor fibres a stainless steel needle with a bared tip of $3 \mathrm{~mm}$ was placed near the nerve at a standard distance from it by adjusting it until the threshold of the motor response was $0.5-$ $0.8 \mathrm{~mA}$. The remote electrode was placed at the same level as the near-nerve electrode at a distance of

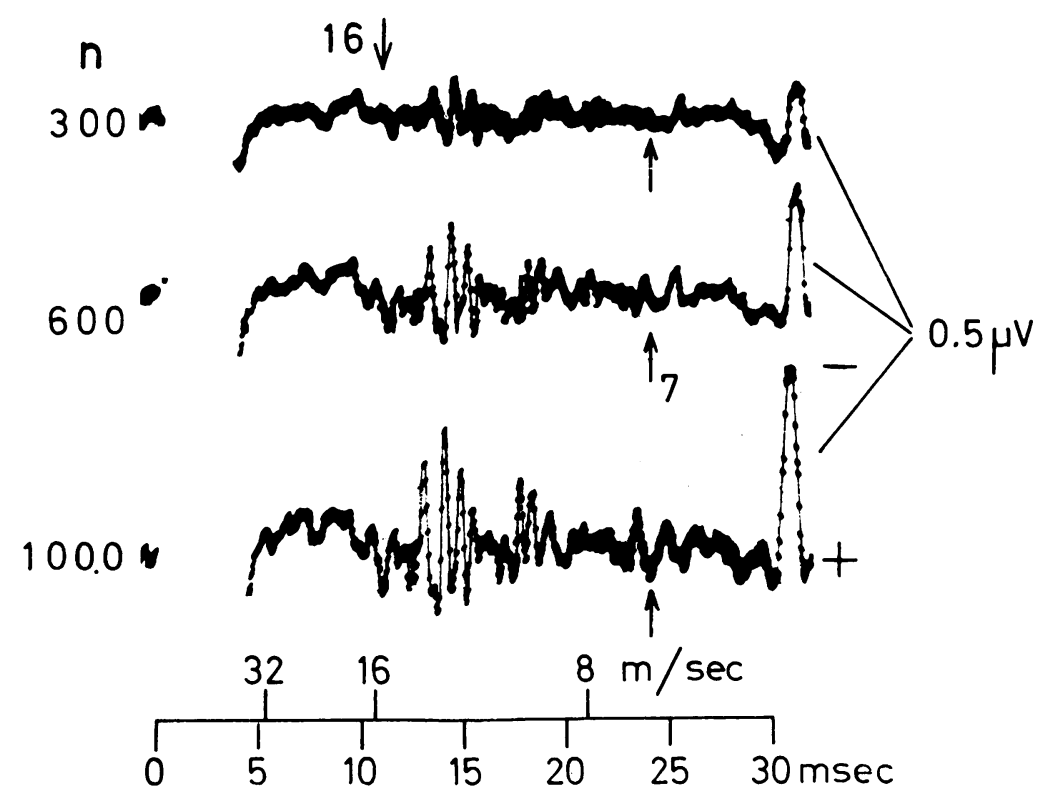

FIG. 1. Procedure to distinguish small components in the sensory potential from noise. The amplitude of the components increased proportionally with that of the calibration signal $(0.5 \mu \mathrm{V})$ when an increasing number $(\mathrm{n})$ of responses were averaged. The figure at the arrow below the trace gives the minimum velocity $(7 \mathrm{~m} / \mathrm{sec})$ and above the trace the maximum velocity $(16 \mathrm{~m} / \mathrm{sec})$. Sixtynine year old woman (E.E.P.) with carpal tunnel syndrome. Onset of symptoms one year ago. Stimulus to digit III and recording at wrist. Here and in the following figures the temperature near the nerve was kept at 35 to $37^{\circ} \mathrm{C}$. 
4-6 cm from it. The electrodes were discarded after having been used once.

In patients with entrapment of the median nerve at the wrist action potentials evoked in $\mathrm{m}$. abductor pollicis brevis or in the muscles of the hypothenar eminence served as indicators of motor conduction. A concentric electrode $\left(0.07 \mathrm{~mm}^{2}\right.$ tip area) placed in the endplate zone or an $80 \mu$ stainless steel wire placed transversely through the centre of the belly of the muscle was used for recording (Wagner and Buchthal, 1972). The response amplitude recorded with a wire electrode was on the average half of that recorded with a concentric electrode.

The amplifier used to record sensory potentials had low noise and short blocking time (Andersen and Buchthal, 1970). Motor unit potentials were recorded by means of a commercial amplifier (DISA 14C11).

To record sensory potentials of less than $4 \mu \mathrm{V}$ and to record slow components, we used electronic averaging of 500 to 2,000 traces $(1 / \mathrm{sec})$. When 500 responses were averaged, components with an amplitude of $0.05 \mu \mathrm{V}$ could be identified by their shape; with 1,000 responses amplitudes of $0.01-$ $0.03 \mu \mathrm{V}$ could be distinguished from noise. When averaged with a resolution of $40 \mu \mathrm{sec} /$ point the steepest positive-negative deflection in the potential $(150 \mu \mathrm{sec})$ was determined by four points with a maximum error on the amplitude of $10-20 \%$. To ascertain the same resolution (number of points per unit time) at different latencies a delay of 4-20 msec was used between stimulus and sampling. To determine the delay necessary to record the slowest components a pilot sampling was performed with 400 points distributed over $25 \mathrm{msec}(60 \mu \mathrm{sec} /$ point $)$.

The terminal components of the potential were identified from noise by their shape and when they increased in size with the number of responses sampled as did a calibration signal (Fig. 1). The slowest components were verified when they were reproduced in consecutive samplings - that is, when nerve stimuli were repeated and the responses were averaged $500,1,000$, and 2,000 times. The reproducible pattern of potentials indicates that the slow components originated from slowly conducting fibres and not from repetitive firing. Repetitive firing was demonstrated in motor fibres (Kugelberg and Cobb, 1951) and in carpal tunnel syndrome the pattern of repetitive firing varied from stimulus to stimulus (Simpson, 1956).

The maximum sensory conduction velocity was determined from the latency to the initial positive

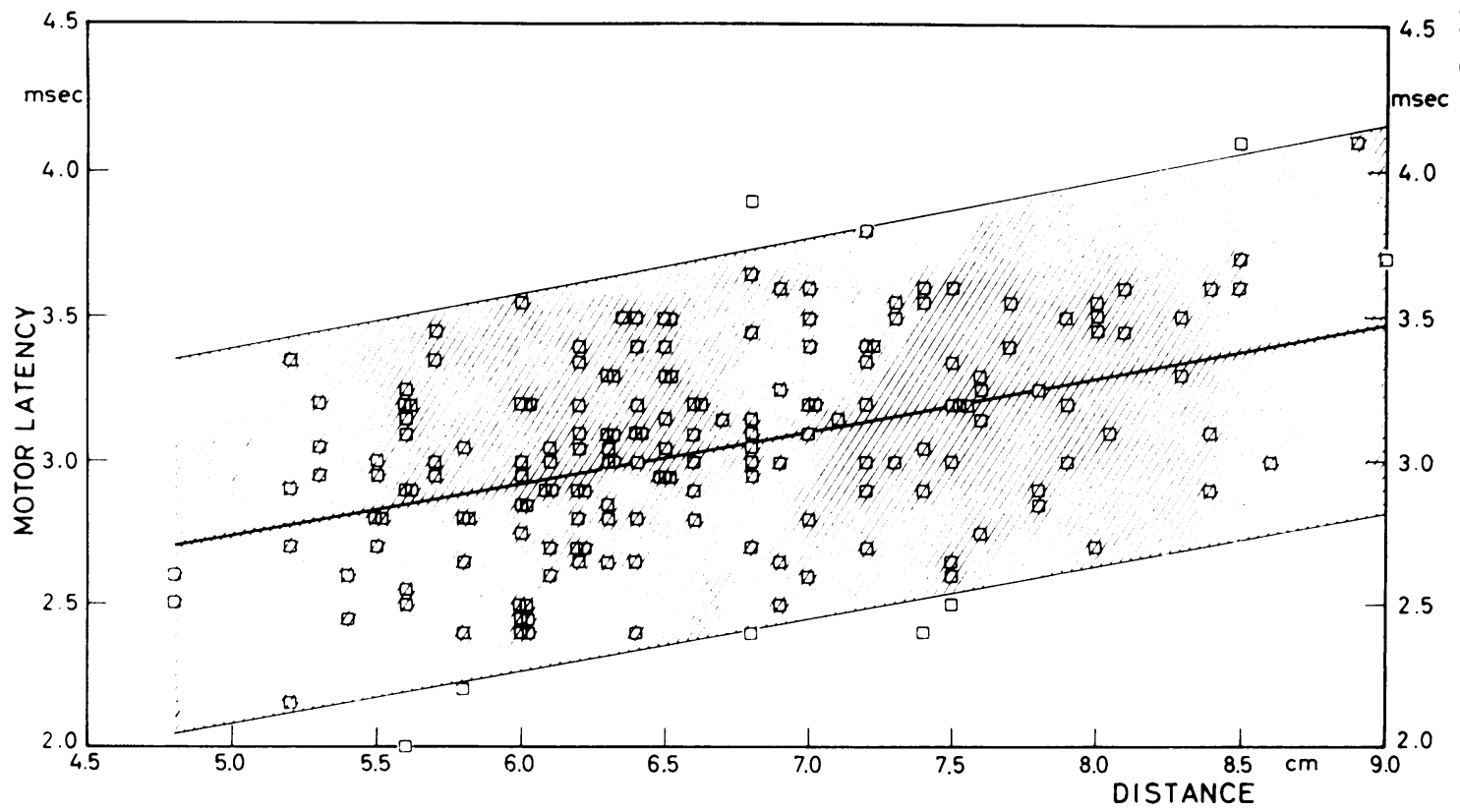

FIG. 2. Increase in motor latency with increasing distance of conduction from wrist to $m$. abductor pollicis brevis in 182 normal subjects. The latencies were corrected to 50 years of age (Fig. 10). The hatched area indicates the $95 \%$ confidence range. 
peak of the potential, which may or may not be the main component. The minimum conduction velocity was determined from the latency to the peak of the last component distinguishable from noise in the averaged response $(500-1,000$ responses).

Motor conduction time was determined from the latency to the initial deflection from the base line of the muscle action potential.

Abnormalities were evaluated by comparison with findings in large groups of normal subjects. To accept a finding in the individual patient as abnormal we require a $99 \%$ probability that the finding does not occur in normals of the same age (upper or lower $99 \%$ confidence limit).

The confidence limits of amplitude were the same whether determined from the cumulative frequency distribution or from the standard deviation log amplitude.

The ratio of sensory velocity and motor latency in the median and ulnar nerve in patients with carpal tunnel syndrome was compared with that in normal subjects (see Figs 4, 10,11). The normal variation from subject to subject was obtained in 17 subjects in whom both nerves were examined. Deviations outside the $95 \%$ confidence limit were considered abnormal.

SOURCES OF ERROR Errors important in the context of this study are as follows:

1. The electrode placed near the median nerve invariably picked up a potential from the radial nerve when digit I was stimulated. Ordinarily the response from radial nerve did not obscure the onset of the potential from median nerve (Buchthal and Rosenfalck, 1971b).

2. When the sensory potential was split up in many components there could be uncertainty as to whether maximum conduction velocity should be calculated from the latency of the first component even when it was smaller than subsequent ones. This uncertainty was observed only when there was marked slowing from digits to wrist, and then both the first and the larger component were so much delayed that conduction velocity, no matter how calculated, was much slower than normal. The uncertainty could be more disturbing when velocity was calculated from wrist to elbow, since components differing in latency may represent different fibres at wrist and at elbow (see Fig. 8). Calculated from the latency of the first component, nine of 144 conduction velocities from wrist to elbow were faster than ever found in normal nerve and hence erroneous.

3 . When $\mathrm{m}$. abductor pollicis brevis was completely denervated the electrode was placed near the nerve at wrist in the following way: (a) An electrode was placed near the median nerve at elbow by adjusting it to the lowest threshold of the action potential in the flexor muscles of the forearm. (b) Stimuli were applied to the median nerve at the wrist adjusting the electrode at wrist to maximum response amplitude of the nerve action potential at the elbow. In this way a sensory potential was recorded from the median nerve at the wrist in the nine patients in whom $\mathrm{m}$. abductor pollicis brevis was completely denervated.

4. An antidromically activated sensory potential may be picked up by the electrode in $\mathrm{m}$. abductor pollicis brevis and obscure the onset of the muscle action potential (Gutmann, 1969; Mavor and Shiozawa, 1971). The sensory potential is conducted in volume from the palmar branch of the thumb (Fiaschi, 1973).

5. When the stimulus at the wrist spreads to the ulnar nerve the electrode in the thenar eminence may pick up a potential of normal latency originating from ulnar-innervated muscles. A stimulus at the elbow activates only the median nerve, the latency to the abductor pollicis brevis muscle being prolonged. The conduction velocity from elbow to wrist will then be calculated erroneously as too slow.

6. Communication between the median and the ulnar nerve in the upper part of the forearm is present in about $15 \%$ of persons (Mannerfeldt, 1966) and causes a stimulus of the median nerve at the elbow to activate an ulnar-innervated muscle in the thenar eminence with a shorter latency than that of $\mathrm{m}$. abductor pollicis brevis. The potential in the ulnarinnervated muscle is picked up by the electrode in $\mathrm{m}$. abductor pollicis brevis. When the latency from the wrist to $\mathrm{m}$. abductor pollicis brevis is prolonged in the face of normal latency from the elbow, the potential has passed from the elbow via an anastomosis along the ulnar nerve. Under such conditions calculation of conduction velocity from elbow to wrist will give unreasonably high values. The anomaly can be easily detected by recording from the hypothenar eminence when the median nerve is stimulated at the elbow.

7. The latency to the onset of the muscle action potential increased with the distance between the stimulating cathode at the wrist and the recording electrode in the muscle (Fig. 2, P $<0.001$, corrected to 50 years of age).

In the median nerve the slope of the regression line was $0 \cdot 18$ corresponding to a conduction velocity of $56 \mathrm{~m} / \mathrm{sec}$; this is $5 \mathrm{~m} / \mathrm{sec}$ below the velocity from elbow to wrist at 50 years of age.

In this report latencies were corrected to a standard distance of $6.5 \mathrm{~cm}$ for the median and $7.0 \mathrm{~cm}$ for the ulnar nerve (Wagner and Buchthal, 1972).

In patients with entrapment of the median nerve at the elbow the stimulus was applied $5 \mathrm{~cm}$ proximal 
and $5 \mathrm{~cm}$ distal to the epicondylar line and at the wrist. Motor conduction was measured to $\mathrm{m}$. flexor digitorum profundus and sublimis and to $\mathrm{m}$. abductor pollicis brevis. Sensory potentials were evoked by stimulation of digits I and III and recorded at the wrist and below and above the site of entrapment.

The temperature of the surface of the arm was kept at $36-38^{\circ} \mathrm{C}$ corresponding to $35-37^{\circ} \mathrm{C}$ near the nerve. An infra-red heating element $(45 \mathrm{~cm}$ long, $500 \mathrm{~W}$ ), controlled by a thermocouple on the forearm, was placed about $20 \mathrm{~cm}$ above the extremity.

ELECTROMYOGRAPHY In patients with a carpal tunnel syndrome 112 abductor pollicis brevis muscles were examined. In addition, the muscles of the hypothenar eminence were examined in 14 patients without and in 11 patients with signs and symptoms of ulnar nerve involvement in addition to entrapment of the median nerve.

In patients with entrapment of the median nerve at the elbow, $\mathrm{m}$. flexor digitorum sublimis, $\mathrm{m}$. flexor digitorum profundus, $\mathrm{m}$. flexor pollicis longus, and $\mathrm{m}$. abductor pollicis brevis were examined.

The following electromyographic parameters were used: (1) A pattern of discrete electrical activity during full effort indicates loss of motor units (Buchthal and Clemmesen, 1941). (2) The average duration and amplitude of $20-40$ different motor unit potentials sampled randomly during weak or moderate effort. The normal values matched for age were taken from Sacco et al. (1962). A deviation exceeding $20 \%$ in duration was abnormal $(P<0.05)$. (3) An increased incidence of polyphasic potentials (more than four phases). Among 20-30 motor unit potentials in normal muscle three may be polyphasic corresponding to an upper limit of normal of $12 \%(\mathrm{P}<0.05$, Caruso and Buchthal, 1965). (4) The number of sites within a muscle with fibrillation potentials or positive sharp waves. Two or more such sites outside the end-plate zone indicate denervation (Buchthal and Rosenfalck, 1966b). (5) The number of sites with fasciculation potentials (Trojaborg and Buchthal, 1965) and with pseudomyotonic bursts.

PATIENTS AND CONTROLS Patients were excluded from our series who had disease that predisposes to peripheral neuropathy; included were three patients with mild diabetes mellitus but without clinical and electrophysiological signs of diabetic neuropathy.

The material comprises 117 consecutive patients with signs and symptoms suggestive of carpal tunnel syndrome referred in 1965-72 to the Laboratory of Clinical Neurophysiology at the Rigshospital. The mean age was 55 years and 11 patients were 30 years old or less; 84 were women, 33 men.

Half the patients had severe weakness and wasting of $\mathrm{m}$. abductor pollicis brevis and in nine there was neither voluntary activity nor response to electrical stimulation in this muscle. Nearly all patients complained of paraesthesia in the area of the median

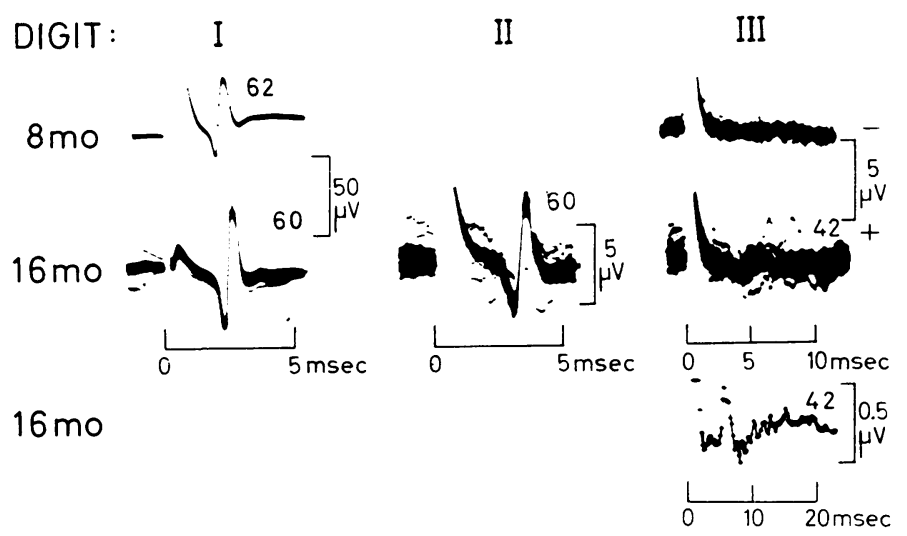

FIG. 3. Sensory potentials after transection of the funiculi from digit III in the median nerve at wrist, without damage to the funiculi from digit I. Upper traces: eight months after suture of the divided funiculi of the nerve. Middle traces: recovery at 16 months. Lower trace: response from digit III recorded at high gain. The figures above the traces denote the maximum conduction velocity in $\mathrm{m} / \mathrm{sec}$. Twenty-seven year old man (B.B.W.). The latency from wrist to m. abductor pollicis brevis was normal. 

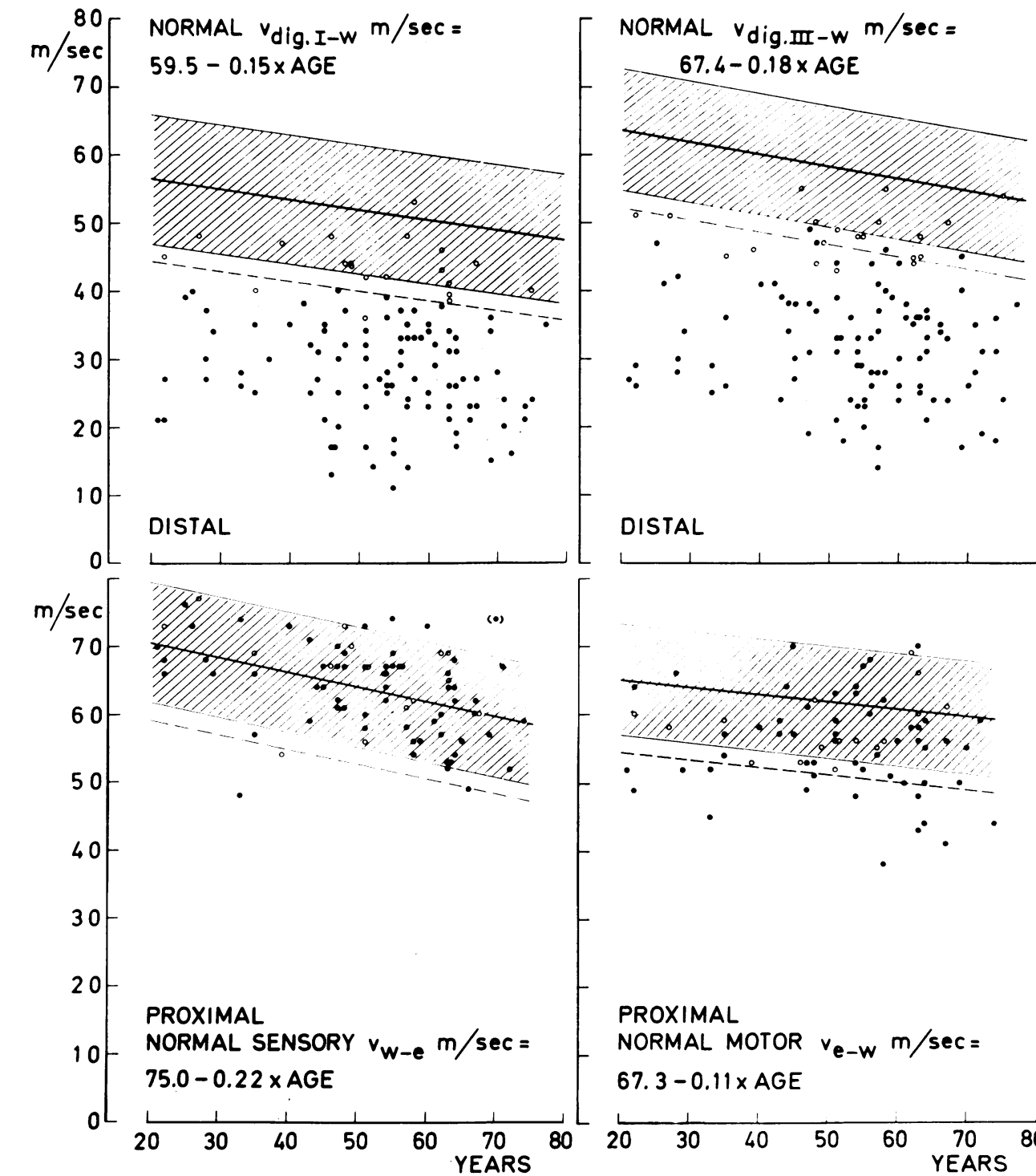

DISTAL
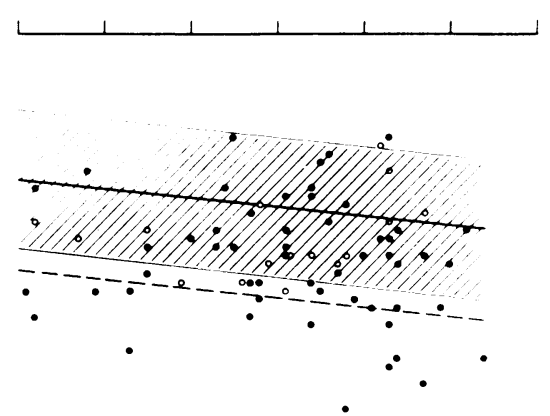

PROXIMAL

NORMAL MOTOR $v_{e-w} \mathrm{~m} / \mathrm{sec}=$

67. $3-0.11 \times A G E$

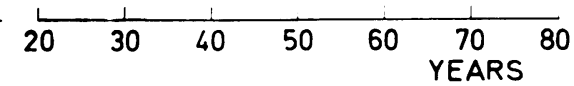

FIG. 4. Sensory and motor conduction velocity in the median nerve as a function of age in patients with a carpal tunnel syndrome. Above, left: sensory velocity from digit I to wrist. Above, right: from digit III to wrist (111 patients, 118 hands). Below, left: sensory velocity from wrist to elbow, stimulus to digit III (81 patients). Below, right: motor velocity from elbow to wrist (76 patients). $\bigcirc:$ severe slowing from digit I or III to wrist. $\bigcirc:$ borderline or normal velocity (but slowing from palm to wrist). The hatched area represents the range of velocities $(2 \times S D)$ obtained from normal median nerves (190 sensory, 100 motor). The dashed line indicates the lower $99 \%$ confidence limit. The equations of the regression lines of normal conduction velocities are given in each diagram.

nerve, $60 \%$ had pain and half had decreased sensitivity to touch and pin-prick.

Eighteen patients had clinical signs and symptoms of involvement of the ulnar nerve in addition to affection of the median nerve.
Eleven patients had signs and symptoms suggestive of unilateral entrapment of the median nerve at elbow. In four the cause was trauma, in seven it was unknown. All complained of pain of acute onset in the volar aspect of the elbow and the forearm, 
tenderness of the pronator teres muscle, weakness of the long flexors acting on the thumb, digit II and digit III.

On examination all patients showed diminished force in the distal phalanx of the thumb and digit II (m. flexor digitorum profundus); six had weakness of digit III as well, and in four force in the superficial flexor and abductor pollicis brevis muscles was also diminished.

Sensation of touch and pinprick was diminished in six patients, localized in four to digits I to III, in two to the palm of the hand.

CONTROLS The normal values of sensory and motor conduction velocity in the median nerve were based on findings in 190 normal subjects, including 47 investigated by Nielsen (1973). Data from ulnar nerves were obtained from 100 controls and 96 patients with carpal tunnel syndrome, excluding those with clinical signs and symptoms of affection of the ulnar nerve and with diabetes mellitus. Since conduction velocity, amplitude of the sensory potential and motor latency did not differ in patients with carpal tunnel syndrome from controls, both groups were pooled (see pp. 352 and 356).

\section{RESULTS}

PATIENTS WITH ENTRAPMENT OF THE MEDIAN NERVE AT WRIST. TOPOGRAPHY OF NERVE FIBRES FROM DIGITS I AND III Sensory conduction velocity was determined both from digit I and from digit III to the wrist because these branches may be affected differently. The cutaneous fibres from digit I and from the first, second, and third interspace lie in separate funiculi within the median nerve up to $2 \mathrm{~cm}$ proximal to the radial styloid line (Sunderland, 1945). Moreover, the transverse carpal ligament often contains a separate tunnel for the passage of the thenar branch (Johnson and Shrewsbury, 1970). This arrangement may explain why partial transection of the nerve may spare the cutaneous fibres from digit I (Fig. 3) and the muscular branch to the thenar eminence, and why the fibres from digit I may be more affected than those from digit III.

SENSORY CONDUCTION IN THE MEDIAN NERVE When electronic averaging was used, a sensory

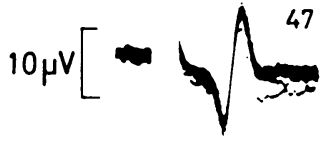

$2 \mu V$
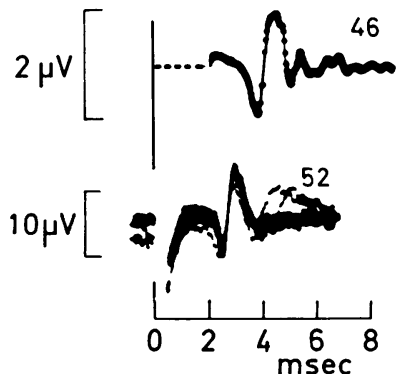
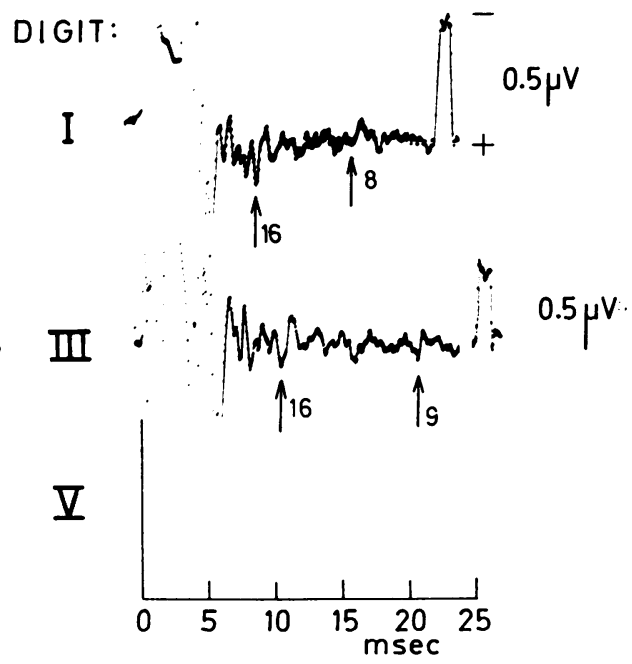

FIG. 5. Slowing in maximum sensory conduction velocity (left, low gain) from digit III to wrist and normal velocity from digits $I$ and $V$ to wrist in a patient with carpal tunnel syndrome. The minimum velocity (right, high gain, 1,000 responses) was diminished both from digit I and digit III to wrist. The figures above the traces denote the maximum velocities $(\mathrm{m} / \mathrm{sec})$. The arrows below the traces indicate the latency corresponding to the average minimum velocity of normal nerve $(16 \mathrm{~m} / \mathrm{sec})$ and those found in the patient $(8$ and $9 \mathrm{~m} / \mathrm{sec})$. Thirtynine year old woman (I.E.H.) with carpal tunnel syndrome; onset of symptoms two and a half months ago. The latency to $m$. abductor pollicis brevis was normal. 

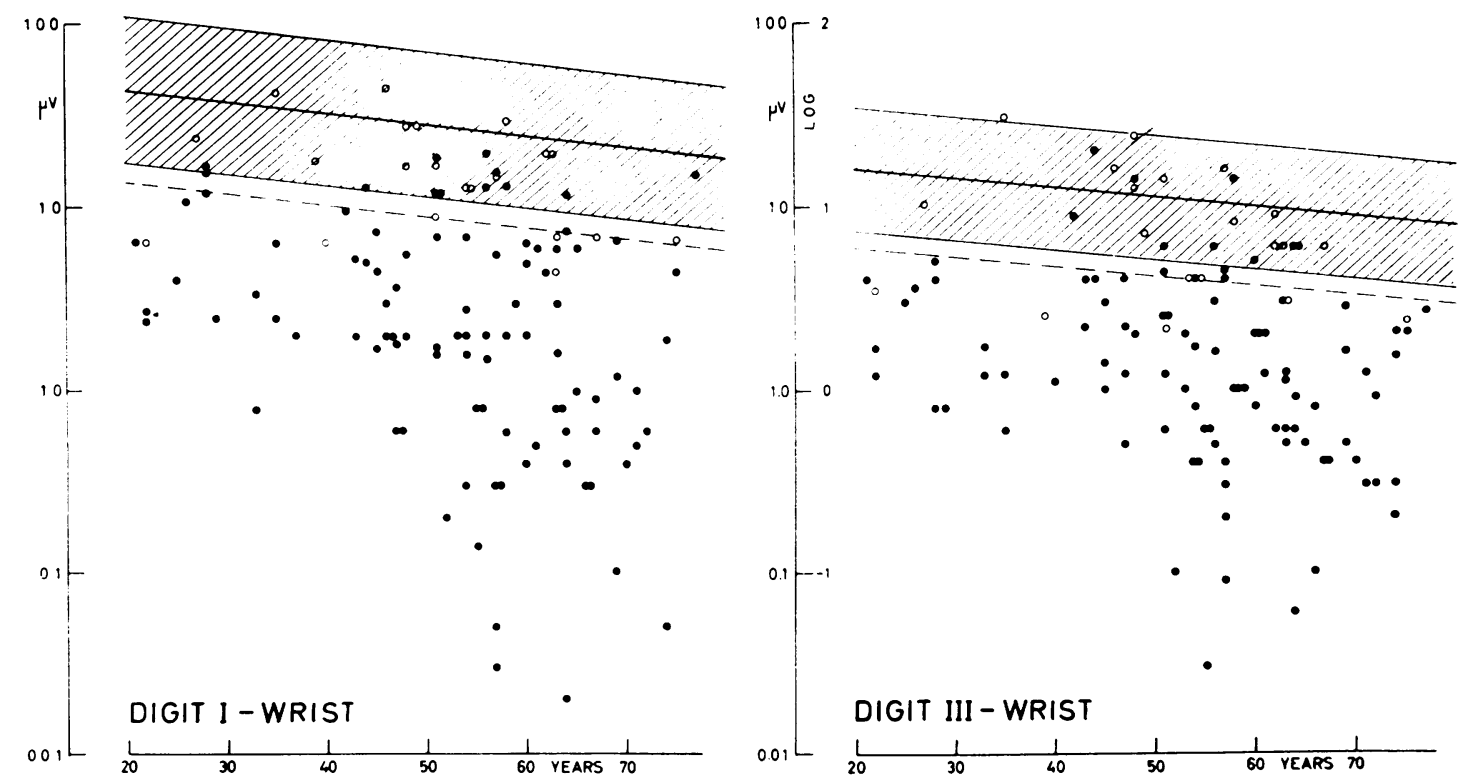

FIG. 6. Amplitude of the sensory potential (log scale) recorded from the median nerve at wrist as a function of age in 117 patients with a carpal tunnel syndrome. Left: stimulus to digit I. Right: stimulus to digit III. The hatched area represents the range of amplitudes $(2 \times S D)$ obtained in 190 normal median nerves; the dashed line indicates the lower $99 \%$ confidence limit. The regression lines for normal nerves were: log ampl. dig. $I=1.757-0.0060 \times$ age; log ampl. dig. III=1.31I-0.0050 × age. $\bigcirc$, O : see legend to Fig. 4.

potential was recorded along the median nerve in all 111 consecutive patients with signs and symptoms of carpal tunnel syndrome. In seven patients sensory conduction was examined in the median nerves of both hands. In 110 hands the sensory response was obtained along the segment both from digit I and from digit III to wrist. Six patients are described separately whose symptoms were suggestive of carpal tunnel syndrome and whose maximum sensory and motor conduction were normal.

Maximum conduction velocity from digit to wrist This was slowed below the $99 \%$ confidence limit of normal when digit I or when digit III was stimulated or along both branches of the nerve in $86 \%$ of 118 hands (Fig. 4). When conduction was slowed the amplitude of the sensory response was decreased in all but 17 hands. In three-fourths of the hands slowing was by more than $40 \%$, in onefourth by more than $50 \%$. In most patients slowing was as pronounced from digit I as from digit III to the wrist. However, in 11 hands slowing was confined to the segment of nerve from one of the digits (Fig. 5). In 16 hands sensory conduction was normal or borderline in the segments of the nerve from both digit I and digit III to the wrist; in 13 of these the amplitude of the sensory potentials was normal as well.

Amplitude of sensory potential at wrist In splitup potentials the second or third spike was often larger than the fastest component (Fig. 1). The largest component was diminished below the $99 \%$ confidence limit in $73 \%$ of 118 hands. In about half the nerves, in which the sensory potentials were diminished, the potential was less than $2 \mu \mathrm{V}$ and could be identified only by electronic averaging. A reduction to less than $1 \mu \mathrm{V}$ was more apt to occur among patients who were more than 45 years old; in five patients the potential was $0 \cdot 1 \mu \mathrm{V}$ or less, below $1 \%$ of normal (Fig. 6).

In most patients the amplitude of the sensory potentials was as diminished when stimulating 
digit $\mathrm{I}$ as digit III $(\mathrm{P}<0.001)$. However, in 13 patients the amplitude was outside the $99 \%$ confidence limit when stimulating one digit and within it when stimulating the other digit. In 28 patients the amplitude was normal both when stimulating digit I and digit III; in 17 of these maximum conduction from digit to wrist was normal as well; the only abnormality in sensory conduction was then slowing from the palm to the wrist (Buchthal and Rosenfalck, 1971b).

Slow components of sensory potential at wrist were analysed in 56 patients. That part of the sensory potential that normally is a smooth and triphasic spike with a duration of $1.2-1.5 \mathrm{msec}$, was split up into 5-10 components. The rise time of the individual components was one-third

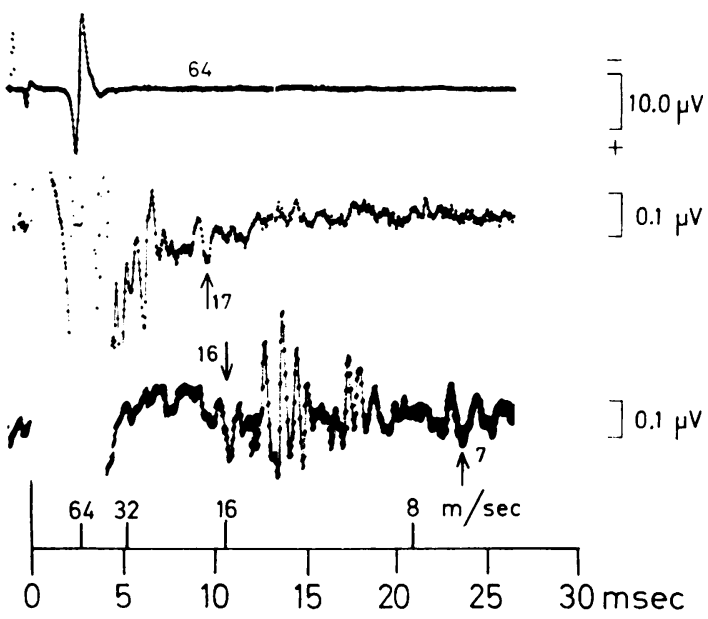

FIG. 7. Sensory potentials in normal median nerve and in a patient with carpal tunnel syndrome. Above: normal nerve, potential recorded at low gain. Middle: the same potential as above at 80 times higher gain (1,000 responses). Below: Potential in carpel tunnel syndrome recorded at high gain (1,000 responses). Stimulus to digit III, recording at wrist. The figures above the traces give the maximum velocities, below the traces the minimum velocities $(\mathrm{m} / \mathrm{sec})$. Normal subject (E.B.) 28 year old male. Patient (E.E.P.) 69 year old woman (see Fig. 1). Lower scale: conduction time. Upper scale: conduction velocity.

that of the normal potential. With high gain the total duration of the normal potential was 4 to $10 \mathrm{msec}$. In two-thirds of the patients the potentials were dispersed over 10-30 msec (Fig. 7). The increased temporal dispersion corresponds to a slowing in minimum velocity (normal mean $16 \mathrm{~m} / \mathrm{sec}, 95 \%$ confidence limit $12 \mathrm{~m} / \mathrm{sec}$ ). The minimum velocity could be as slow as 4-7 m/sec.

At the average latency of the slowest component in normal nerve, the amplitude was 0.2-3 $\mu \mathrm{V}, 4-60$ times greater than the slowest components in normal nerve $(0.05-0.1 \mu \mathrm{V})$. In half the nerves in which the potentials were abnormally split up, the first burst of potentials was followed by one or two separate bursts several msec apart (Figs 7, 8).

Maximum velocity from wrist to elbow This was obtained in 81 forearms (stimulus to digit III), including 69 hands with severe slowing from digit to wrist. The proximal velocities lay around the average for normal nerves, and all except two were within the $99 \%$ confidence limit (Fig. 4).

Proximal sensory conduction velocity, though within the range of normal, tended to be the lower, the slower the proximal motor conduction $(\mathrm{P}<0.05$, velocities normalized to 50 years of age).

At the elbow the amplitude of the sensory potential was two-thirds that at the wrist. When the response at the wrist was $1-4 \mu \mathrm{V}$ in amplitude and consisted of four or five initial spikes followed by small components, the general appearance of the potential at the elbow was the same, but consisted of six to eight initial components (Fig. 8). The increase in temporal dispersion from wrist to elbow was of the same order as in normal nerve. The spike components were as steep at the elbow as at the wrist.

Maximum conduction velocity from palm to wrist This was obtained in 44 patients. It was slowed in all and nearly always slower than the velocity from digit III to the palm. The degree of the slowing from digit III to the palm increased with the slowing across the flexor retinaculum (Fig. 9, left). When the velocity from digit to palm was severely slowed $(37 \mathrm{~m} / \mathrm{sec}$ or less, nine patients), the amplitude of the response recorded at the palm was diminished to less than $1 \%$ of normal $(0.05-0.1 \mu \mathrm{V})$ indicating loss of many fibres 7-13 $\mu \mathrm{m}$ in diameter.

If the velocity from digit III to the palm were 

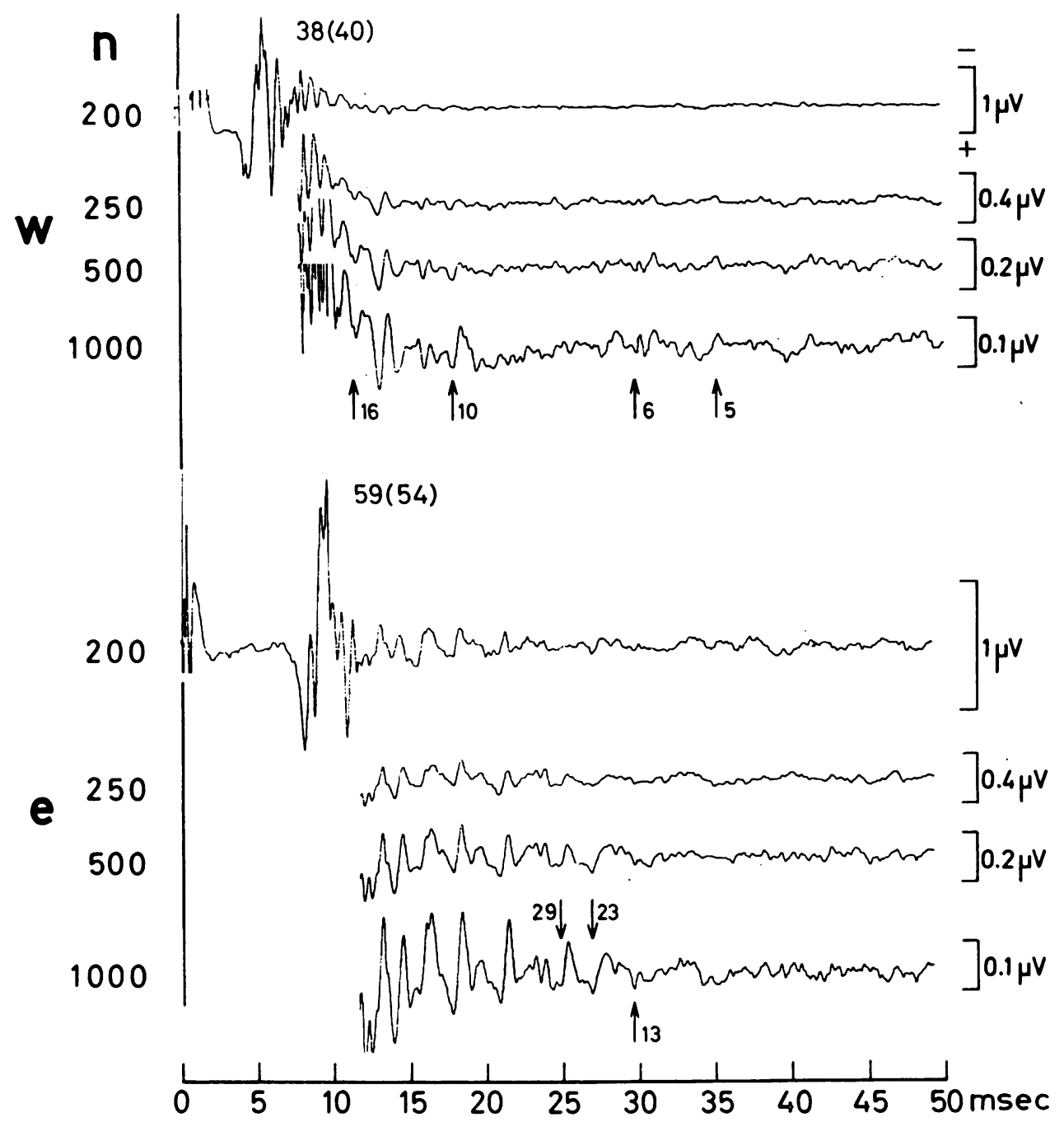

FIG. 8. Transmission of fast and slow components of the sensory potential from wrist to elbow along the median nerve in carpal tunnel syndrome. $\mathrm{w}$ : recorded at wrist, e: recorded at elbow. Stimulus $60 \mathrm{~mA}$ to digit III. The figures above the upper traces give the maximum conduction velocity $(\mathrm{m} / \mathrm{sec})$ from digit to wrist and from wrist to elbow referred to the large initial positive component at wrist; numbers in parentheses are conduction velocity referred to the first small positive component at wrist. The velocity from wrist to elbow with stimulus to digit I was $61.5 \mathrm{~m} / \mathrm{sec}$. The slow components were distinguished from noise by their increase in amplitude with the number (n) of responses sampled. The minimum velocity at wrist was 6 or $5 \mathrm{~m} / \mathrm{sec}$ (arrows below trace). These components were within the noise level at elbow. The arrow at 16 indicates the minimum velocity ( $\mathrm{m} / \mathrm{sec}$ ) along normal nerve. The last large component at wrist $(10 \mathrm{~m} / \mathrm{sec}$, arrow below trace) was conducted to elbow at 29 or $23 \mathrm{~m} / \mathrm{sec}$ (arrows above trace). The slowest component which could be identified at elbow was conducted from digit to elbow at $13 \mathrm{~m} / \mathrm{sec}$ (arrow below trace). Thirty-four year old woman (K.B.B.J.) with carpal tunnel syndrome during pregnancy. Onset of symptoms three months ago. 

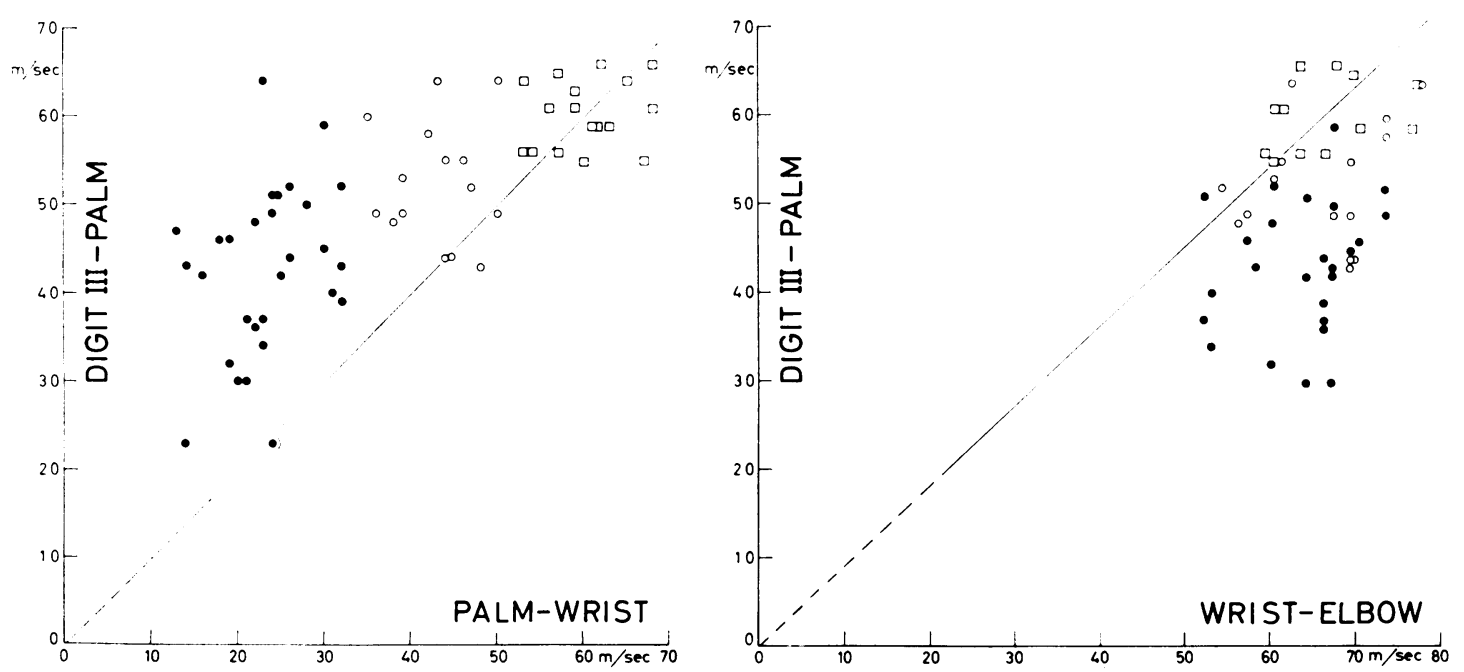

FIG. 9. Maximum sensory conduction velocity from digit III to palm as a function of the velocity from palm to wrist (left) and from wrist to elbow (right). $\square$ : normal subjects. $\bigcirc$ : mild slowing from palm to wrist (borderline from digit to wrist). 0 : severe slowing from palm to wrist. The lines through zero assume equal (left, slope 1) or proportionate (right, slope 0.91) slowing in the segments examined. Maximum velocities above the line (left) and below the line (right) indicate that fibres which conduct at a diminished rate below the flexor retinaculum conduct faster distally and proximally to it.

as slow as that from palm to wrist, the one plotted against the other would fall on a line of slope 1 which passes through zero (Fig. 9, left). In fact, when the velocity from digit III to the palm was plotted against the velocity from palm to wrist, most values fell above this line, indicating slowed conduction across the flexor retinaculum, out of proportion to normal velocity or mild slowing along surviving fibres from digit to palm. If a similar argument were applied to the velocity from digit III to the palm as related to that from the wrist to the elbow, most values fell below the line with slope 1 (Fig. 9, right), indicating that the same fastest fibres conducted slower from digit III to the palm than from the wrist to the elbow. The localized slowing confirms previous findings in a smaller group of patients (Buchthal and Rosenfalck, 1971b).

MOTOR CONDUCTION IN MEDIAN NERVE 1 . In $82 \%$ of 111 hands the motor latency from the wrist to $\mathrm{m}$. abductor pollicis brevis was prolonged above the $99 \%$ confidence limit of normal; in $6 \%$ it was borderline (Fig. 10). Latencies longer than $7 \mathrm{msec}$ were seen only in patients over
45 years of age. In one-fourth of the patients with slowing in sensory fibres the distal motor latency was normal. Conversely, in four of 19 patients in whom sensory potentials from digits to wrist were normal, distal motor latency was abnormal.

2. In two-thirds of 69 patients the velocity from elbow to wrist was below the average of normal, but it was below the $99 \%$ confidence limit in only 14 (Fig. 4) (Thomas, 1960; Kaeser, 1963; Thomas et al., 1967, Buchthal and Rosenfalck, 1971b). A long distal latency was sometimes, but not always, associated with proximal slowing in motor fibres. Only 11 of 23 patients with distal motor latency of $6 \mathrm{msec}$ or longer had proximal conduction velocity of less than $52 \mathrm{~m} / \mathrm{sec}$ (below the $99 \%$ confidence limit).

CONDUCTION ALONG ULNAR NERVE Normal findings in the ulnar nerve support the electrophysiological diagnosis of carpal tunnel syndrome.

Excluding 18 patients with clinical findings suggestive of ulnar nerve involvement and three patients with diabetes mellitus, all of the remain- 


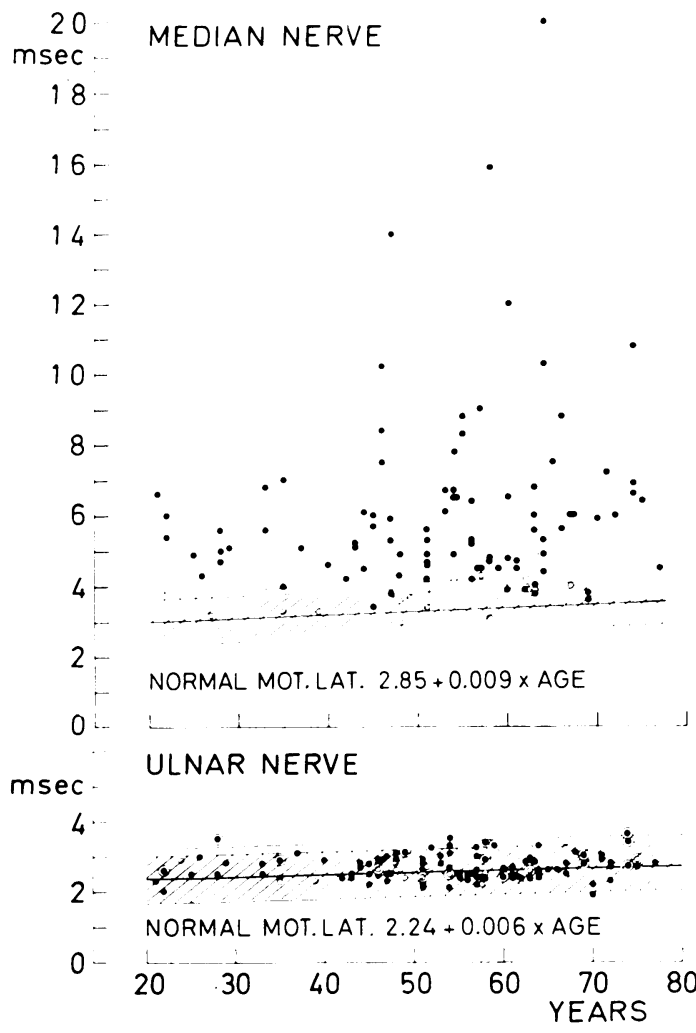

FIG. 10. Latency from wrist to $m$. abductor pollicis brevis (above) and to the muscles of the hypothenar eminence (below) in 111 patients (118 hands) with carpal tunnel syndrome. $\bigcirc$, : see legend to Fig. 4. $\odot$, $\odot:$ patients with clinical signs and symptoms of involvement of the ulnar nerve. The hatched areas represent the range $(2 \times S D)$ obtained from 182 normal median nerves, 100 normal ulnar nerves, as well as 96 normal ulnar nerves from patients with carpal tunnel syndrome. The dashed lines indicate the $99 \%$ confidence limit of normal; the equations of the regression lines for distal latencies are given at the bottom of each diagram.

ing 96 patients had a sensory conduction along the ulnar nerve, an amplitude of the sensory potential and a distal motor latency within the 95 and $99 \%$ confidence limits of controls (Figs 10 and 11).

In the 18 patients with clinical findings suggestive of ulnar nerve involvement as well as slowing along the median nerve across the retinaculum, the electrophysiological examination of the ulnar nerve showed one or several of the following abnormalities: (1) Amplitude of the sensory potential at the wrist diminished to less than half of normal (16 patients). In these patients the site of the lesion of the ulnar nerve was probably at the elbow. (2) Slowing in sensory conduction from digit $\mathrm{V}$ to the wrist (below the $99 \%$ confidence limit in two patients, below the average of normal in 14 patients (Fig. 11)). (3) Slowing in sensory conduction from below to above the cubital sulcus at the elbow in those six patients in whom proximal velocity was determined along the ulnar nerve. (4) Prolonged motor latency from the wrist to the muscles of the hypothenar eminence (two patients). (5) Abnormalities in the electromyographic examination of the muscles of the hypothenar eminence in the 11 patients in whom these muscles were studied.

RATIO OF FINDINGS IN MEDIAN AND ULNAR NERVE In patients with distal slowing in sensory or motor fibres of the median nerve the ratio of sensory velocity or of motor latency in the median and in the ulnar nerve is obviously altered as long as conduction in the ulnar nerve is normal. The question arises whether the ratio can help to detect abnormalities in the median nerve when sensory velocity from digits to wrist or distal motor latency or both were borderline.

The diagnostic yield of the ratio was tested in those 23 patients in whom there was uncertainty because one or both velocities from digits to wrist were above the $99 \%$ confidence limit (Fig. 12). Only in seven patients was the ratio outside the range of normal $(\mathrm{P}<0.05)$ for at least one of the digits. In three patients the ratio was normal on account of slowing along the ulnar nerve. In the same 23 patients the ratio of amplitudes of the sensory potentials was unsuitable as a criterion of abnormality in borderline involvement because of the considerable scatter of the amplitudes in normal nerve.

The diagnostic yield of the ratio of motor latency in the median and ulnar nerves was tested in 17 patients in whom the motor latency from the wrist to $\mathrm{m}$. abductor pollicis brevis was below the $99 \%$ confidence limit (Fig. 12). In only two was the ratio outside the range of normal $(\mathrm{P}<0.05)$.

Finally, we have selected those 10 patients in whom there was doubt because motor latencies 

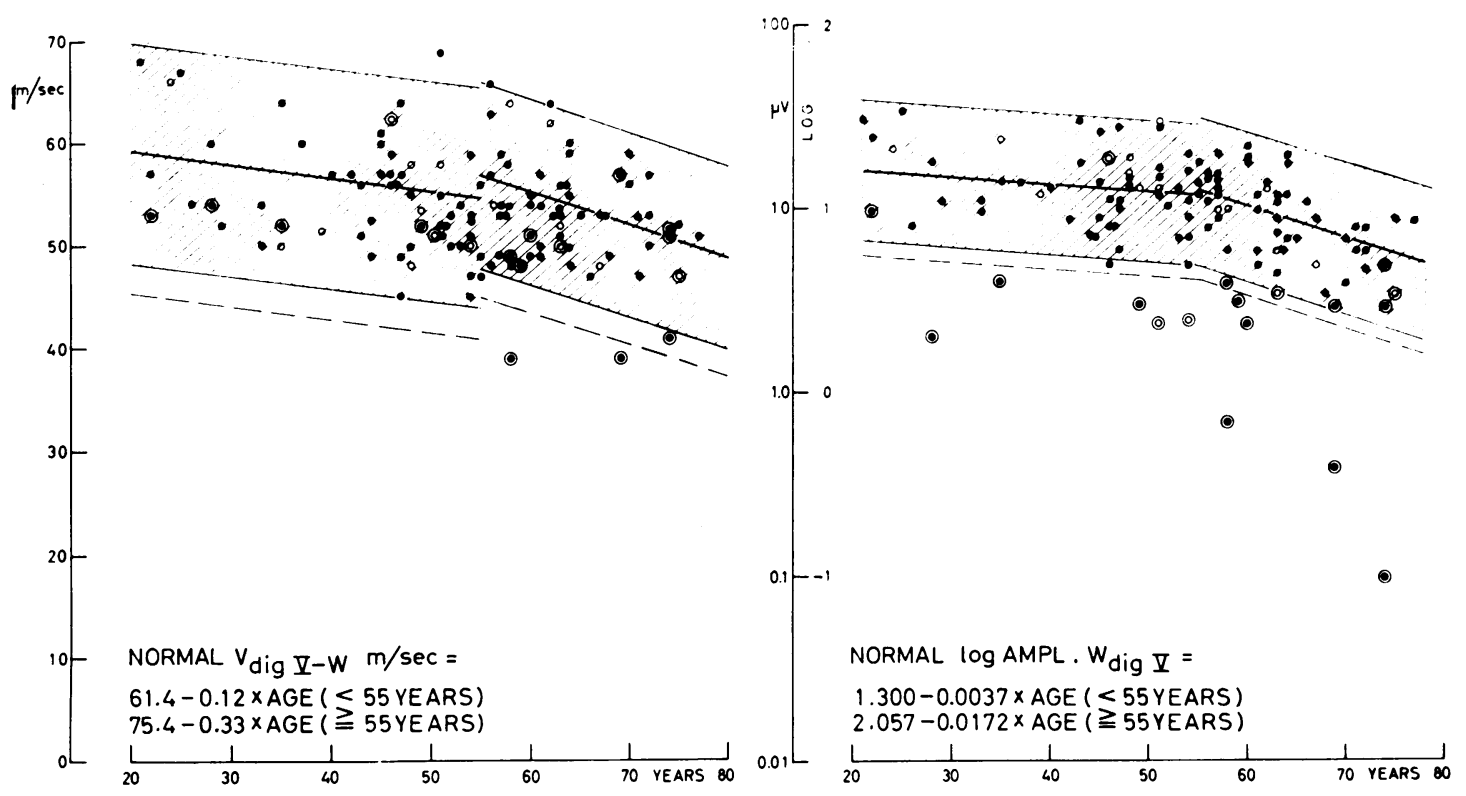

FIG. 11. Sensory conduction velocity (left) and amplitude of the sensory potential at wrist (right, $\log$ scale) ino $\dot{\omega}$ the ulnar nerve as a function of age in 117 patients with carpal tunnel syndrome. $\bigcirc, O$ : findings in the median? nerve, see legend to Fig. 4. $\odot, \odot:$ patients with clinical signs and symptoms of involvement of the ulnar nerve@ The hatched areas represent the normal range of velocity and amplitude $(2 \times S D)$ and the dashed lines the $99^{\circ} \%$ confidence limit of normal. The equation of the regression lines of normal velocities and amplitudes are given ats the bottom of each diagram (100 ulnar nerves from controls and 96 from patients with carpal tunnel syndrome)

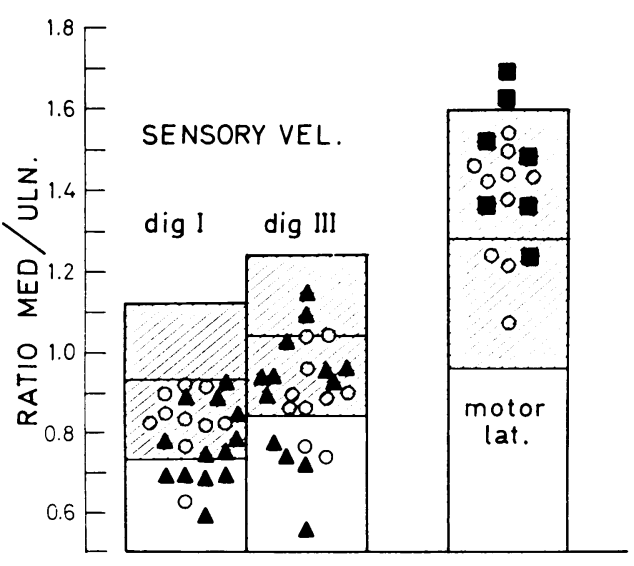

were normal, sensory conduction in the median nerve from digits to wrist was either normal or, if slightly slowed, the amplitudes of the sensory potentials were normal (Fig. 12). The ratio of sensory velocity from digit I or III to the wrist to that from digit $\mathrm{V}$ to the wrist was diminished in only two patients. In all 10 patients the ratio of
FIG. 12. Ratio of findings in the median and ulnar nerve in patients with mild carpal tunnel syndrome. The hatched areas represent the $95 \%$ confidence range of normal ratios. Left: ratio of sensory velocities from digits to wrist (23 patients). Right: ratio of distal motor latencies (17 patients). $\mathbf{\Delta}$ : normal sensory velocity from digit I or digit III to wrist $(P<0.01,13$ patients). $\bigcirc$ : normal sensory velocity from digit $I$ and digit III to wrist and normal distal motor latency in the median nerve $(P<0.01,10$ patients with slowing from palm to wrist). $\square$ : normal distal motor latency in the median nerve $(P<0.01$, seven patients $)$.

motor latencies was normal, leaving eight patients in whom severe slowing from palm to wrist was the sole evidence of carpal tunnel syndrome.

DISTAL SENSORY CONDUCTION AND MINIMUM CONDUCTION VELOCITY AFTER DECOMPRESSION In 13 patients the median nerve was reinvestigated 


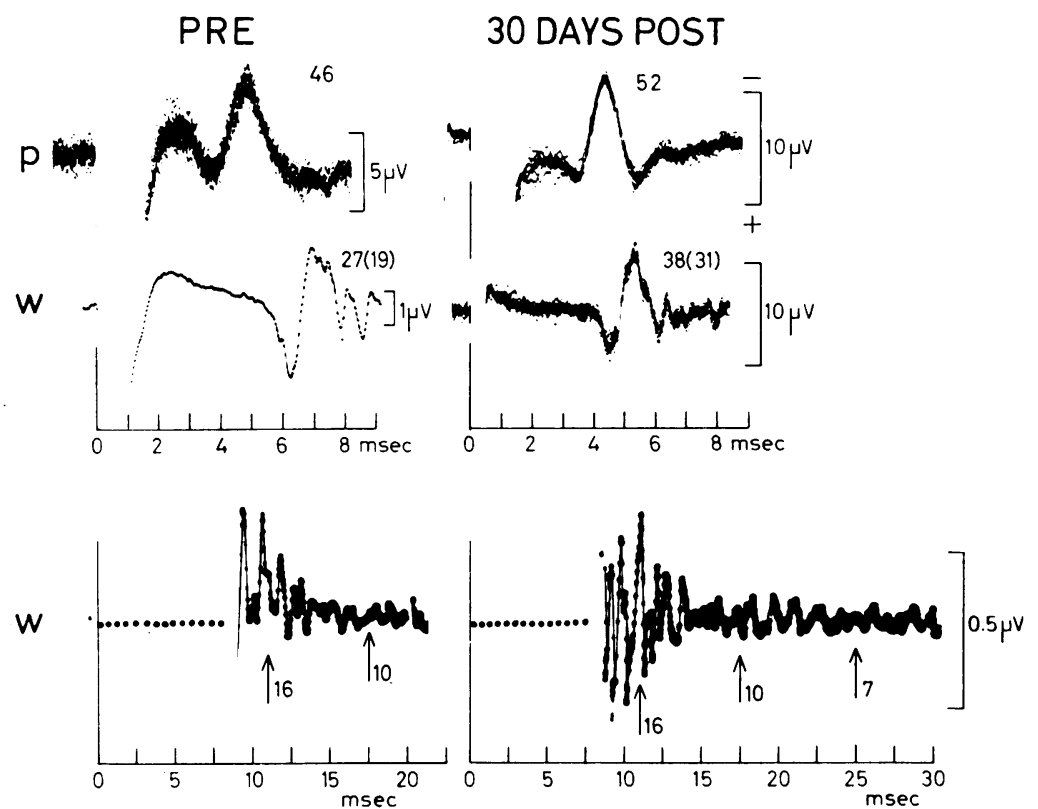

FIG. 13. Recovery of maximum and minimum sensory conduction 30 days after surgical division of the flexor retinaculum. Increase in amplitude of the sensory potential at palm (p) and at wrist $(\mathrm{w})$; increase in maximum sensory velocity from digit III to palm and from digit III to wrist. Below: the potentials at wrist recorded with high gain (500 responses). The slow components had longer latencies after than before decompression. The figures above the traces give the velocities in milliseconds distal to the site of recording; parentheses: the velocity from palm to wrist. The dotted lines indicate the delay before sampling. The arrows below the averaged responses indicate the average minimum velocity in normal nerve $(16 \mathrm{~m} / \mathrm{sec})$, the minimum velocity before $(10 \mathrm{~m} / \mathrm{sec})$ and after decompression $(7 \mathrm{~m} / \mathrm{sec})$. Note the two bursts of slow components after decompression. Twenty-one year old woman (B.L.J.) with carpal tunnel syndrome.

after surgical division of the flexor retinaculum. Pain and paraesthesia had disappeared within the first month after decompression. The rate of recovery in sensory and motor conduction confirms findings of previous studies (Goodman and Gilliatt, 1961; Thomas et al., 1967; Kemble, 1968; Hongell and Mattsson, 1971).

Three patients were reinvestigated distal to the site of compression 15,30 , or 40 days postoperatively (Fig. 13). As early as 15 days after decompression the velocity from palm to wrist had increased by $10 \mathrm{~m} / \mathrm{sec}$. The slow components had longer latencies and higher amplitudes than before decompression, the minimum velocity decreasing from 10 to $7 \mathrm{~m} / \mathrm{sec}$ in the one patient and from 12 to $6 \mathrm{~m} / \mathrm{sec}$ in the other.

PATIENTS WITH SYMPTOMS OF CARPAL TUNNEL SYNDROME AND NORMAL MOTOR AND SENSORY CONDUCTION In six patients with paraesthesia and pain in the area of the median nerve the cause of the symptoms remained obscure. Maximum sensory and motor conduction in the median and ulnar nerves, as well as the ratio of findings in these nerves, and electromyography of $\mathrm{m}$. abductor pollicis brevis were normal. Sensory conduction from palm to wrist, determined in four patients, was normal. The only abnormality 
was a diminished minimum conduction velocity from digit to wrist in two of the three patients in whom it was determined. One of these patients was re-examined six months after surgical division of the flexor retinaculum; pain and paraesthesia were unchanged.

ELECTROMYOGRAPHY IN 112 ABDUCTOR POLLICIS BREVIS MUSCLES In $91 \%$ of the muscles one or other electromyographic abnormality was found.

1. Pattern of discharge during full effort In half the muscles examined there was discrete activity indicating loss of many motor units. It was present in all muscles whose force was graded at less than 4 but even in $27 \%$ of muscles graded at force 5 (Medical Research Council, 1943). Onethird of the muscles had an interference pattern during full effort.

2. Mean duration and amplitude of motor unit action potentials The mean duration was prolonged by more than $20 \%$ of normal $(\mathrm{P}<0.05)$ in half the muscles; in none was it decreased. Prolonged mean duration was more frequent in muscles with a discrete pattern of discharge $(51 \%)$ than when there was an interference pattern $(11 \%)$. It was twice as frequent in patients whose symptoms had lasted for more than two months, thereafter the incidence was independent of duration.

The mean amplitude of motor unit potentials was increased by more than $50 \%$ in one-fourth of the muscles examined; nearly all had a pattern of discharge which indicated severe or moderate loss of motor units.

3. Incidence of polyphasic potentials In $60 \%$ of the muscles more than $12 \%$ of motor unit action potentials were polyphasic $(\mathrm{P}<0.05)$. Polyphasia was found as often in muscles with normal as in those with prolonged mean duration of motor unit potentials. Though polyphasia was more apt to occur when a discrete pattern of discharge indicated loss of many motor units, yet half of the 30 muscles with an interference pattern showed more than $12 \%$ polyphasic potentials.

4. Spontaneous activity (a) Half the muscles showed fibrillation potentials, positive sharp waves or both in two or more sites of the muscle outside the endplate zone. In the muscles with these signs of denervation $69 \%$ showed both fibrillation potentials and positive sharp waves, $28 \%$ only fibrillation potentials, and $3 \%$ only positive sharp waves. Fibrillation potentials and positive sharp waves occurred twice as often in muscles with a pattern of discrete activity during full effort as in muscles with an interference pattern. Nevertheless, $30 \%$ of muscles with a normal pattern of discharge during full effort showed fibrillation potentials, positive sharp waves or both. Fibrillation and positive sharp waves were recorded as often in muscles with as without prolonged mean duration of motor unit action potentials and with or without an increased incidence of polyphasic potentials. Fibrillation potentials were the only electromyographic abnormality in $7 \%$ of the muscles. They occurred equally often in muscles of patients whose symptoms had lasted less and more than six months. (b) In $18 \%$ of muscles fasciculations were recorded at several sites and in $6 \%$ one of several 'pseudomyotonic' bursts.

5. Relation between electromyographic finding and distal motor latency A pattern of discret activity during full effort was found in more thay half the patients with prolonged latency and $i \bar{\Psi}$ $90 \%$ of those with a latency of $8 \mathrm{msec}$ or longer. Sixty per cent of muscles with an abnormal latency showed fibrillation potentials or positive sharp waves as compared with $30 \%$ of muscles with a normal latency. Neither the mean duration of motor unit potentials nor the incidence of polyphasic potentials was related to the motor latency.

6. A pattern of discrete activity during full effort was recorded in one-third of the patients with mild or borderline slowing in sensory conduction as compared with two-thirds of the patients with marked slowing.

ELECTROMYOGRAPHY OF 25 MUSCLES OF THE HYPOTHENAR EMINENCE In 14 patients without clinical signs of ulnar nerve involvement the muscles of the hypothenar eminence were studied. The pattern of discharge was normal, as was the mean duration of motor unit action potentials. One patient had fibrillation potentials 
TABLE

ELECTROPHYSIOLOGICAL ABNORMALITIES IN 11 PATIENTS WITH ENTRAPMENT OF MEDIAN NERVE AT ELBOW

\begin{tabular}{|c|c|c|c|c|c|c|c|c|c|c|c|}
\hline $\begin{array}{l}\text { Age (yr) and sex } \\
\text { EMG }\end{array}$ & $27 \mathrm{M}$ & $18 \mathrm{M}$ & $39 \mathrm{M}$ & $21 \mathrm{M}$ & $44 \mathrm{M}$ & $64 \mathrm{M}$ & $61 \mathrm{M}$ & $60 M$ & $13 \mathrm{~F}$ & $47 \mathrm{~F}$ & $60 \mathrm{~F}$ \\
\hline flex. dig. prof. & $\mathbf{a}$ & $\mathbf{a}$ & o & o & $\mathbf{a}$ & $\mathbf{a}$ & $\mathbf{a}$ & $\mathbf{a}$ & $\mathbf{a}$ & o & $\mathbf{a}$ \\
\hline flex. dig. subl. & $\mathbf{n}$ & $\mathbf{n}$ & $\mathbf{n}$ & $\mathbf{n}$ & $\mathbf{n}$ & $\mathbf{a}$ & a & $\mathbf{n}$ & $\mathbf{a}$ & o & $\mathbf{n}$ \\
\hline abd. poll. brev. & $\mathbf{n}$ & $\mathbf{n}$ & $\mathbf{n}$ & $\mathbf{n}$ & $\mathbf{a}$ & $\mathbf{a}$ & $\mathbf{n}$ & $\mathbf{n}$ & $\mathbf{a}$ & o & $\mathbf{n}$ \\
\hline Latency to & & & & & & & & & & & \\
\hline flex. dig. prof. & $\mathrm{n}$ & $\mathbf{n}$ & o & o & $\mathrm{n}$ & $\mathbf{n}$ & $\mathbf{a}$ & $\mathbf{a}$ & $\mathbf{n}$ & $\mathbf{o}$ & $\mathbf{n}$ \\
\hline flex. dig. subl. & $\mathbf{n}$ & $\mathbf{n}$ & $\mathbf{n}$ & $\mathrm{n}$ & $\mathbf{n}$ & $\mathbf{n}$ & $\mathbf{n}$ & $\mathbf{a}$ & $\mathbf{n}$ & o & $\mathrm{n}$ \\
\hline abd. poll. brev. & $\mathbf{n}$ & $\mathbf{n}$ & $\mathbf{n}$ & $\mathbf{n}$ & $\mathbf{n}$ & $\mathbf{n}$ & $\mathrm{n}$ & $\mathrm{n}$ & $\mathbf{a}$ & o & n \\
\hline $\begin{array}{l}\text { Sensory cond. } \\
\text { below-above elbow }\end{array}$ & $n$ & $n$ & $n$ & $n$ & $n$ & $n$ & $n$ & $n$ & 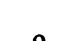 & 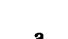 & 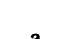 \\
\hline
\end{tabular}

n: normal, a: abnormal, o: voluntarily and electrically evoked responses absent.

in two sites and borderline increase in polyphasic potentials.

Of 17 patients with clinical signs and symptoms of involvement of the ulnar nerve an electromyographic examination was obtained in 11. One or several of the electromyographic parameters were abnormal: discrete activity during full effort was found in five, increase in mean duration of motor unit potentials in nine, increase in the incidence of polyphasic potentials in five, fibrillation and positive sharp waves in three, and polyphasia in five.

PATIENTS WITH ENTRAPMENT OF MEDIAN NERVE AT ELBOW SENSORY AND MOTOR CONDUCTION In 11 patients sensory conduction along three segments of the median nerve (below to above elbow, wrist-elbow, digits-wrist) was examined and was normal in eight (Table). In two of them the motor latency to the deep flexor digitorum muscle was prolonged, one had in addition prolonged latency to the superficial flexor muscle.

Three patients showed abnormalities of sensory conduction, in one sensory potentials were absent. This was the only patient in whom there was slowing in motor fibres to $\mathrm{m}$. abductor pollicis brevis localized to the segment of the nerve from above to below the site of entrapment. In the second patient sensory conduction was slowed and sensory potentials were diminished in amplitude both below and above the site of entrapment. The deep and superficial flexor muscles of the fingers and $\mathrm{m}$. abductor pollicis brevis were completely denervated. In the third patient slowing in sensory fibres was confined to the segment from below to above the site of entrapment and potentials were reduced in amplitude throughout. Motor latencies and motor conduction velocity were normal.

ELECTROMYOGRAPHIC FINDINGS The deep flexor digitorum and flexor pollicis longus muscles were affected in all 11 patients (Table). There was discrete activity of diminished amplitude during full effort $(<1 \mathrm{mV})$ in eight and one or the other muscle was completely denervated in three patients. There were fibrillation potentials and positive sharp waves in five or six sites of the muscles. The superficial flexor digitorum muscle was affected in four patients. The abductor pollicis brevis muscle had an interference pattern of discharge of normal amplitude during full effort (eight patients) the only abnormality being fibrillation potentials in three.

\section{DISCUSSION}

PATIENTS WITH CARPAL TUNNEL SYNDROME The electrophysiological diagnosis of carpal tunnel syndrome poses difficulties (1) when distal motor latency is normal; (2) when sensory conduction along the median nerve from digits to wrist is normal; (3) when the amplitude of the sensory potential is so reduced that conventional recording does not reveal a sensory potential; and (4) when there is involvement of the ulnar nerve in addition to an entrapment of the median nerve.

Distal motor latency was normal or borderline in one-fourth of our patients with clinical and other electrophysiological signs of carpal tunnel syndrome. To identify an abnormal latency, findings in the individual patient were compared with the average of normal subjects of the same 
age (Fig. 10). If we had used the average from subjects 40-60 years of age, a prolonged latency in a 20 year old patient might not have been recognized. The distal motor latency increased by $0.18 \mathrm{msec} / \mathrm{cm}$ distance of conduction (Fig. 2). This increase has not been observed when stimulating with surface electrodes (McQuillen and Gorin, 1969). We have required a $99 \%$ probability for a latency to be judged as prolonged. Nevertheless, the limit of normal was lower in our series than in previous studies (Kaeser, 1963, Thomas et al., 1967) because of rigorous control of temperature, correction to a standard distance, and matching for age.

Sensory conduction from digits to wrist was normal or borderline in $25 \%$ of patients. In these patients exclusion of the segment of nerve from digit to palm with near-normal conduction velocity was the procedure of choice (Buchthal and Rosenfalck, 1971b). Slowing was then significant from palm to wrist except in six patients (p. 353) in whom the cause of signs and symptoms remained unexplained.

In most patients conduction and amplitude of the potentials evoked by stimulation of digit I were as abnormal as the potential evoked by stimulation of digit III. Nevertheless, an abnormal conduction would have been overlooked in $10 \%$ of the patients if only one of the fingers had been examined. Thus in $10 \%$ of the patients conduction was slowed when stimulating digit I and normal when stimulating digit III and vice versa. The cutaneous fibres supplying digit I and the first interspace are aggregated in separate funiculi of the nerve (Sunderland, 1945).

The interindividual variation in amplitude of the sensory potential was great, as great when recording with needle (Fig. 6,11) as with surface electrodes (Mayer, 1963; Kaeser, 1966; Thomas et al., 1967; Sato et al., 1972). The $99 \%$ confidence limit was 30 to $50 \%$ of the average. However, only with a needle electrode placed near the nerve could a sensory potential be detected in all patients when electronic averaging was used. In most previous studies surface electrodes were used for recording and sensory potentials could not be recognized at the wrist in 20 to $70 \%$ of the patients and were not recorded at the elbow (Kaeser, 1966; Thomas et al., 1967; Kopell and Goodgold, 1968; Hongell and Mattsson, 1971; Sedal et al., 1973).
When the procedure did not allow a sensory potential to be recorded from the median nerve at the wrist, a normal potential from the ulnar nerve favours the diagnosis of carpal tunnel syndrome. Conversely, abnormalities in the potentials recorded from the ulnar nerve do not exclude a carpal tunnel syndrome, since $15 \%$ of our patients also had clinical evidence of ulnar involvement.

Sedal et al. (1973) excluded from their group of patients with carpal tunnel syndrome all those with clinical evidence of an ulnar nerve lesion. Nonetheless, in one-third of their carpal tunnel patients they found that in the ulnar nerve mean sensory and motor latency were longer and amplitude of the sensory potentials was lower than in controls. They interpreted their findings to indicate a more generalized neuropathy in these patients.

In our series, excluding 18 patients with clinical evidence of ulnar nerve involvement and three patients with diabetes mellitus, findings in the ulnar nerve did not differ in patients with carpal tunnel syndrome and in normal controls In both groups there was some evidence of subclinical ulnar nerve lesion above 55 years of age seen in Fig. 11 by the steeper slope of the regression lines relating sensory conduction velocity and amplitude of the sensory potentials to age. We interpret this finding as indicating subclinical traumatic damage to the ulnar nerve rather than evidence of generalized neuropathy.

When both the median and the ulnar nerves were affected, the ratio between findings can obviously be of no diagnostic help. One might wonder why the ratio in most patients with mild involvement of the median nerve did not help more to single out involvement than comparison with findings in normal nerve corrected for age, temperature, and distance. It is true that the ratio more or less excludes errors due to temperature and age. However, the most important error which remains is then that of the measurement of conduction distance. This becomes greater when the ratio is used because two conduction distances enter the calculations.

Proximal to the site of compression, motor fibres were affected differently from sensory. Motor conduction from elbow to wrist was slowed in two-thirds of the patients (Fig. 4) (Simpson, 1956; Thomas, 1960; Ebeling et al., 
1960; Kaeser, 1963; Thomas et al., 1967; Buchthal and Rosenfalck, 1971b), though the slowing was not proportional to the increase in distal latency. Thus a decrease in proximal motor velocity is no evidence against a carpal tunnel syndrome. On the other hand, maximum sensory conduction velocity was normal (Fig. 4). Also later components of the sensory response conducted at normal rate from wrist to elbow, the increase in temporal dispersion after conduction from wrist to elbow being the same as in normal nerve.

In patients with borderline slowing along the median nerve from digits to wrist and with normal motor latency slowing from palm to wrist was the only way to localize entrapment. Moreover, the faster velocity from digit to palm than from palm to wrist contributes to distinguish entrapment at the wrist from a distal demyelinating neuropathy.

The fact that the same fibres in which conduction was severely slowed from palm to wrist conducted at normal rate proximal to the flexor retinaculum, indicates that the slowing is due to a localized attenuation in the rate of conduction (demyelination) and not to loss of the largest fibres (Fig. 9). Similarly, the same fibres that showed slowing from palm to wrist conducted faster in the more distal segment of the nerve, though they did not have normal velocity, when slowing across the retinaculum was severe. Mild slowing from digit to palm in the face of severe slowing from palm to wrist could be explained either by the constriction in diameter shown to occur distal to the site of compression (Weiss and Hiscoe, 1948) or by inclusion of a short demyelinated stretch of the nerve in the $8-9 \mathrm{~cm}$ long segment from digit to palm. While the slowing thus seems to be due to local demyelination, the low amplitudes (less than one-tenth of normal) found in many patients indicate that there was loss of many fibres as well (Thomas and Fullerton, 1963).

Increased amplitude of the components of the sensory potential at the wrist at the latency of the slowest components in normal nerve is also compatible with a displacement of the latencies of fast fibres to longer latencies (Figs 5, 7, 8, 13). Prolonged latency of the slowest components is not necessarily evidence of slowing in demyelinated fibres. It may indicate conduction along incompletely remyelinated or regenerated fibres. That slow components occurred in bursts, the longest latencies of which were longer one month after than before decompression would favour the assumption of remyelination (Fig. 13). In a number of patients bursts of slow components occurred even before decompression, consistent with remyelination or axonal regeneration even during the state of compression (Fig. 7).

No attempt was made to localize entrapment at the wrist by comparing electromyographic findings in a distal muscle (abductor pollicis brevis) with those in the finger flexors of the forearm. Electromyographic abnormalities were found in $30 \%$ of the abductor pollicis brevis muscles to which the distal motor latency was normal.

In half the patients a discrete pattern of discharge during full effort indicated loss of many motor units. That this was also found in $30 \%$ of muscles with normal force is consistent with an increase in size of surviving motor units by peripheral sprouting. Reinnervation can also explain the prolonged duration and the increased amplitude of motor unit potentials. In none of the muscles was there a decrease in mean duration. This is of interest in view of the variable findings reported recently by Oosterhuis et al. (1972). The increased incidence of polyphasic potentials in $60 \%$ of the muscles is less specificit can either indicate reinnervation or destruction of fibres in a motor unit.

Fibrillation potentials and positive sharp waves were present in half the muscles; this confirms previous findings (Thomas et al., 1967; Kopell and Goodgold, 1968; Hongell and Mattsson, 1971). It was the only electromyographic abnormality in $7 \%$ of muscles. Fasciculation potentials were seen more often among our patients than among Thomas et al.'s (1967) patients $(18 \%$ as compared with $8 \%)$. In most muscles they were not noticed clinically and were more apt to confuse the electromyographer than the clinician.

PATIENTS WITH ENTRAPMENT OF MEDIAN NERVE AT ELBOW The signs and symptoms of median nerve compression at the elbow may point to an affection of the main trunk or to an involvement of the anterior interosseous branch only. It may 
start acutely or subacutely without antecedent trauma (Kiloh and Nevin, 1952; Thomas, 1962; Farber and Bryan, 1968; Schmidt and Eiken, 1971) or suddenly as a complication of fracture of the forearm or supracondylar fracture of the humerus (Warren, 1963; Spinner and Schreiber, 1969). Motor conduction (four patients, Farber and Bryan, 1968; Vichare, 1968; O'Brien and Upton 1972) and distal sensory conduction (one patient, O'Brien and Upton, 1972) were normal. Electromyography of the deep flexors of the fingers in the forearm (seven patients, Stern et al., 1967; Farber and Bryan, 1968; Spinner and Schreiber, 1969; Schmidt and Eiken, 1971; O'Brien and Upton, 1972) showed a reduced interference pattern and fibrillation potentials in some. The common abnormality in our 11 patients was palsy of the deep flexor muscle which acts on the distal phalanx of digits I, II, and often III, associated with electromyographic abnormalities in these muscles. In four patients this was the only abnormality, consistent with a lesion confined to the anterior interosseous nerve.

In seven patients the distribution of the lesion pointed to a more extensive affection of the median nerve: three had abnormal sensory conduction, two had electromyographic abnormalities in the superficial as well as in the deep flexor muscle of the forearm and in the abductor pollicis brevis muscle. In one patient the latency was prolonged to the deep flexor muscle, but electromyographic abnormalities were found also in the superficial flexor muscle. In the last patient motor latencies were prolonged to both the deep and the superficial flexor muscles, but electromyographic abnormalities were confined to the deep flexor muscle.

As compared with entrapment at the wrist, entrapment at the elbow was less apt to cause abnormalities in conduction. They were found only when there was evidence of a lesion of the main trunk of the median nerve and then in four of the seven patients.

\section{SUMMARY}

Determination of sensory and motor conduction and quantitative electromyography were evaluated in 117 patients with signs and symptoms of entrapment of the median nerve at the wrist and 11 with entrapment at the elbow. Findings were compared with those in normal nerves and muscles at constant temperature, corrected for age and for distance of conduction.

CARPAL TUNNEL SYNDROME When findings were borderline the ratio of findings in the median and ulnar nerve did not add information of diagnostic significance. In 111 patients maximum and minimum sensory conduction velocities were slowed either from digits to wrist or, if these were borderline, from palm to wrist.

In $10 \%$ of the patients slowing was confined to the branches of the nerve either from digit I or digit III. In $25 \%$ the distal motor latency in the median nerve was normal. In six patients maximum sensory conduction and distal motor $\vec{\circ}$ latency in the median nerve and electromyography of $\mathrm{m}$. abductor pollicis brevis were normal.

A sensory potential was recorded in all patients, in half it was less than $2 \mu \mathrm{V}$. Slowing is due to local attenuation of the rate of conduction $\omega$ rather than to loss of large fibres: The same fas $\vec{t}+\overrightarrow{0}$ fibres which conducted slowly from palm to wrist conducted $10-20 \mathrm{~m} / \mathrm{sec}$ faster from digit to palm and at normal rate from wrist to elbow.

In addition to increased temporal dispersiois the low amplitude was due to loss of fibres. $7-13 \mu \mathrm{m}$ in diameter. The sensory potentias recorded in the median nerve were split up into many components, which often appeared in bursts. At the longest latency recorded in normal nerve the slow components were larger than normal, indicating that the responses from fast fibres were displaced to longer latencies.

Fifteen per cent of the patients had clinical and electrophysiological signs of an ulnar nerve lesion in addition to the carpal tunnel syndrome. If these are excluded all of the remaining 96 patients had a sensory conduction along the ulnar nerve, an amplitude of the sensory potential, and a distal motor latency within the 95 and $99 \%$ confidence limits of controls. One or 8 several electromyographic abnormalities were found in $90 \%$ of the abductor pollicis brevis $ᄋ$ muscles examined including fasciculations in $\rightarrow$ $18 \%$ of the patients examined.

ENTRAPMENT AT ELBOW In four patients the lesion was confined to the anterior interosseous nerve with electromyographic abnormalities in 
the deep finger flexors of the forearm, although the latency was normal. In seven patients the lesion was localized to the trunk of the median nerve with prolonged latency to or electromyographic abnormalities in the deep and superficial flexors or in both. In three sensory conduction was slowed.

\section{REFERENCES}

Andersen, V. O., and Buchthal, F. (1970). Low noise alternatin current amplifier and compensator to reduce stimulus artefact. Medical and Biological Engineering, 8, 501-508.

Buchthal, F., and Clemmesen, S. (1941). On the differentiation of muscle atrophy by electromyography. Acta Psychiatrica et Neurologica (Kbh.), 16, 143-181.

Buchthal, F., and Rosenfalck, A. (1966a). Evoked action potentials and conduction velocity in human sensory nerves. Brain Research, 3, 1-122.

Buchthal, F., and Rosenfalck, P. (1966b). Spontaneous electrical activity of human muscle. Electroencephalography and Clinical Neurophysiology, 20, 321-336.

Buchthal, F., and Rosenfalck, A. (1971a). Sensory potentials in polyneuropathy. Brain, 94, 241-262.

Buchthal, F., and Rosenfalck, A. (1971b). Sensory conduction from digit to palm and from palm to wrist in the carpal tunnel syndrome. Journal of Neurology, Neurosurgery, and Psychiatry, 34, 243-252.

Caruso, G., and Buchthal, F. (1965). Refractory period of muscle and electromyographic findings in relatives of patients with muscular dystrophy. Brain, 88, 29-50.

Ebeling, P., Gilliatt, R. W., and Thomas, P. K. (1960). A clinical and electrical study of ulnar nerve lesions in the hand. Journal of Neurology, Neurosurgery, and Psychiatry, 23, 1-9.

Farber, J. S., and Bryan, R. S. (1968). The anterior interosseous nerve syndrome. Journal of Bone and Joint Surgery, 50-A, 521-523.

Fiaschi, A. (1973). Observations on the sensory nature of the intramuscular nerve action potential. Journal of Neurology, Neurosurgery, and Psychiatry, 36, 509-513.

Gilliatt, R. W., and Sears, T. A. (1958). Sensory nerve action potentials in patients with peripheral nerve lesions. Journal of Neurology, Neurosurgery, and Psychiatry, 21, 109-118.

Goodman, H. V., and Gilliatt, R. W. (1961). The effect of treatment on median nerve conduction in patients with the carpal tunnel syndrome. Annals of Physical Medicine, 6, 137-155.

Gutmann, L. (1969). The intramuscular nerve action potential. Journal of Neurology, Neurosurgery, and Psychiatry, 32, 193-196.

Hongell, A., and Mattsson, H. S. (1971). Neurographic studies before, after, and during operation for median nerve compression in the carpal tunnel. Scandinavian Journal of Plastic and Reconstructive Surgery, 5, 103-109.

Hunt, J. Ramsay (1911). The thenar and hypothenar types of neural atrophy of the hand. American Journal of Medical Science, 141, 224-241.

Hunt, J. Ramsay (1914). The neural atrophy of the muscles of the hand, without sensory disturbances. Review of Neurology and Psychiatry, 12, 137-148.

Johnson, R. K., and Shrewsbury, M. M. (1970). Anatomical course of the thenar branch of the median nerve-usually in a separate tunnel through the transverse carpal ligament. Journal of Bone and Joint Surgery, 52-A, 269-273.
Kaeser, H. E. (1963). Diagnostische Probleme beim Karpaltunnelsyndrom. Deutsche Zeitschrift für Nervenheilkunde, 185, 453-470.

Kaeser, H. E. (1966). Das sensible Nervenaktionspotential und seine klinische Bedeutung. Deutsche Zeitschrift für Nervenheilkunde, 188, 289-299.

Kemble, F. (1968). Clinical and electrophysiological improvement from the carpal tunnel syndrome. Electromyography (Louvain), 8, 27-38.

Kiloh, L. G., and Nevin, S. (1952). Isolated neuritis of the anterior interosseous nerve. British Medical Journal, 1, $850-851$.

Kopell, H. P., and Goodgold, J. (1968). Clinical and electrodiagnostic features of carpal tunnel syndrome. Archives of Physical Medicine and Rehabilitation, 49, 371-375.

Kugelberg, E., and Cobb, W. (1951). Repetitive discharges in human motor nerve fibres during the post-ischaemic state. Journal of Neurology, Neurosurgery, and Psychiatry, 14, 88-94.

Loong, S. C., and Seah, C. S. (1971). Comparison of median and ulnar sensory nerve action potentials in the diagnosis of the carpal tunnel syndrome. Journal of Neurology, Neurosurgery, and Psychiatry, 34, 750-754.

McQuillen, M. P., and Gorin, F. J. (1969). Serial ulnar nerve conduction velocity measurements in normal subjects. Journal of Neurology, Neurosurgery, and Psychiatry, 32, 144-148.

Mannerfelt, L. (1966). Studies on the hand in ulnar nerve paralysis. A clinical-experimental investigation in normal and anomalous innervation. Acta Orthopaedica Scandinavica, Suppl. 87.

Mavor, H., and Shiozawa, R. (1971). Antidromic digital and palmar nerve action potentials. Electroencephalography and Clinical Neurophysiology, 30, 210-221.

Mayer, R. F. (1963). Nerve conduction studies in man. Neurology (Minneap.), 13, 1021-1030.

Medical Research Council (1943). Aids to the Investigation of Peripheral Nerve Injuries, War Memorandum No. 7. H.M.S.O.: London.

Nielsen, V. K. (1974). Sensory and motor nerve conduction in the median nerve in normal subjects. Acta Medica Scandinavica, 194, 435-443.

O'Brien, M. D., and Upton, A. R. M. (1972). Anterior interosseous nerve syndrome. Journal of Neurology, Neurosurgery, and Psychiatry, 35, 531-536.

Oosterhuis, H. J. G. H., Hootsmans, W. J. M., Veenhuyzen, H. B., and Zadelhoff, I. van (1972). The mean duration of motor unit action potentials in patients with myasthenia gravis. Electroencephalography and Clinical Neurophysiology, 32, 697-700.

Sacco, G., Buchthal, F., and Rosenfalck, P. (1962). Motor unit potentials at different ages. Archives of Neurology (Chic.), 6, 366-373.

Sato, Kinya, Katsui, T., and Sato, Kozo (1972). Sensory conduction in the nerves of the arm and leg in man. Nihon University Journal of Medicine, 14, 23-33.

Schmidt, H., and Eiken, O. (1971). The anterior interosseous nerve syndrome. Case reports. Scandinavian Journal of Plastic and Reconstructive Surgery, 5, 53-56.

Sedal, L., McLeod, J. G., and Walsh, J. C. (1973). Ulnar nerve lesions associated with the carpal tunnel syndrome. Journal of Neurology, Neurosurgery, and Psychiatry, 36, 118-123.

Seyffarth, H. (1951). Primary myoses in the m. pronator teres as cause of lesion of the n. medianus (the pronator syndrome). Acta Psychiatrica (Kbh.), Suppl. 74, 251-254. 
Simpson, J. A. (1956). Electrical signs in the diagnosis of carpal tunnel and related syndromes. Journal of Neurology, Neurosurgery, and Psychiatry, 19, 275-280.

Spinner, M., and Schreiber, S. N. (1969). Anterior interosseous-nerve paralysis as a complication of supracondylar fractures of the humerus in children. Journal of Bone and Joint Surgery, 51-A, 1584-1590.

Stern, M. B., Rosener, L. J., and Blinderman, E. E. (1967). Kiloh-Nevin syndrome. Clinical Orthopaedics and Related Research, 53, 95-98.

Sunderland, S. (1945). The intraneural topography of the radial, median and ulnar nerves. Brain, 68, 243-299.

Thomas, D. F. (1962). Kiloh-Nevin syndrome. Journal of Bone and Joint Surgery, 44-B, 962.

Thomas, J. E., Lambert, E. H., and Cseuz, K. A. (1967). Electrodiagnostic aspects of the carpal tunnel syndrome. Archives of Neurology (Chic.), 16, 635-641.

Thomas, P. K. (1960). Motor nerve conduction in the carpal tunnel syndrome. Neurology (Minneap.), 10, 1045-1050.

Thomas, P. K., and Fullerton, P. M. (1963). Nerve fibre size in the carpal tunnel syndrome. Journal of Neurology, Neurosurgery, and Psychiatry, 26, 520-527.

Trojaborg, W., and Buchthal, F. (1965). Malignant and benign fasciculations. Acta Neurologica Scandinavica, 41, Suppl. 13, 251-254.

Vichare, N. A. (1968). Spontaneous paralysis of the anterior interosseous nerve. Journal of Bone and Joint Surgery, 50-B, 806-808.

Wagner, A. L., and Buchthal, F. (1972). Motor and sensory conduction in infancy and childhood: reappraisal. Developmental Medicine and Child Neurology, 14, 189-216.

Warren, J. D. (1963). Anterior interosseous nerve palsy as a complication of forearm fractures. Journal of Bone and $\bar{F}$ Joint Surgery, 45-B, 511-512.

Wiederholt, W. C. (1970). Median nerve conduction velocity in sensory fibres through the carpal tunnel. Archives of Physical Medicine, 51, 328-330.

Weiss, P., and Hiscoe, H. B. (1948). Experiments on the mechanism of nerve growth. Journal of Experimental Zoology, 107, 315-395. 